\title{
HUBUNGAN SEKTOR TRANSPORTASI DAN GROSS DOMESTIC PRODUCT (GDP) PADA NEGARA ANGGOTA ORGANISASI KERJASAMA ISLAM (OKI) DENGAN MENGGUNAKAN ANALISIS KAUSALITAS GRANGER TAHUN 1986-2015(1)
}

\author{
Baiatus Subbaniyah \\ Mahasiswa Program Studi S1 Ekonomi Islam-Fakultas Ekonomi dan Bisnis-Universitas Airlangga \\ Email :baybaia28@gmail.com \\ Moh. Qudsi Fauzy \\ Departemen Ekonomi Syariah-Fakultas Ekonomi dan Bisnis-Universitas Airlangga \\ Email :Qudsifauzy1@gmail.com
}

\begin{abstract}
:
This study aims to determine the relationship of reciprocity between the transport sector and the GDP on the State member of the OIC. This study uses air transportation of cargo and passengers and GDP using the income calculations. The population in this study is a State member of the OIC, the number of samples used are 15 countries in 1986-2015. The analytical method used in this research is by using the Granger Causality. The results showed that there is a reciprocal relationship between the transport sector and the GDP in two OIC member countries, there are Mozambique and Tunisia, and there is a unidirectional relationship in three OIC member countries, there are Egypt. Arab Rep, Pakistan and Saudi Arabia, and also 10 other OIC member countries, there are Bangladesh, Brunei Darussalam, Indonesia, Jordan, Malaysia, Morocco, Sudan, Suriname, Turkey and Uganda there is no relationship between the transport sector and GDP.
\end{abstract}

Keyword: Granger Causality Test, Transport Sector, Gross Domestic Product (GDP)

\section{PENDAHULUAN}

Abad 21 adalah suatu masa dimana dunia tanpa batas (globalisasi) muncul dalam berbagai aspek kehidupan ekonomi, sosial, budaya, politik yang ditandai dengan revolusi transportasi dan komunikasi. Sebagai salah satu sektor yang memiliki kontribusi penting dalam perekonomian, sektor transportasi mampu memberi peran besar dalam perekonomian suatu Negara (Irawati, 2012)

Sistem transportasi merupakan hal yang penting dan strategis dalam pembangunan di suatu Negara. Menurut Warpani (2002:1) mengatakan bahwa transportasi adalah kegiatan pemindahan orang dan barang dari suatu tempat (asal) ketempat lain (tujuan) dengan menggunakan kendaraan. Sistem transportasi yang andal berfungsi sebagai pendukung pertumbuhan ekonomi dan pengembangan wilayah. Terdapat 3 jenis transportasi public yang dapat digunakan oleh masyarakat yakni transportasi darat, laut dan udara. Sarana transportasi yang ada di darat, laut, maupun udara memegang peranan vital dalam pembangunan aspek sosial-ekonomi melalui fungsi distribusi antara satu daerah dengan daerah yang lain. Sebagaimana di jelaskan dalam surat Ar- Rahmaan 55:24-25 sebagai berikut:

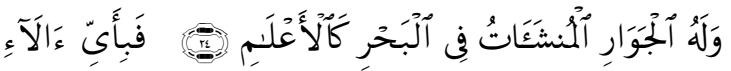

$$
\begin{aligned}
& \text { رَبِكُمَا تُكَذِبَانِ }
\end{aligned}
$$

1) Jurnal ini merupakan bagian dari skripsi Baiatus Subbaniyah, NIM : 041211431150 . Yang diuji pada 12 Januari 2016. 
Subbaniyah, et al/Jurnal Ekonomi Syariah Teori dan Terapan Vol. 4 No. 9 September 2017: 713-725; HUBUNGAN SEKTOR TRANSPORTASI DAN GROSS DOMESTIC PRODUCT (GDP) PADA NEGARA ANGGOTA ORGANISASI KERJASAMA ISLAM (OKI) DENGAN MENGGUNAKAN ANALISIS KAUSALITAS GRANGER TAHUN 1986-2015

Walahu'l-jawÉri'l-munsya'atufi'l- Bahri Ka'l-a'lém. Fabi ‘ai-yi'alÉi Ra'b- BikumÉ TukazibÉn

Artinya: "Dan kepunyaan-Nya lah bahtera-bahtera yang tinggi layarnya di lautan laksana gunung-gunung. Maka nikmat Tuhan-Mu yang manakah yang engkau dustakan?" (Q.S 55:24, Departemen Agama RI. 2002)

Dalam ayat tersebut dapat disimpulkan bahwa selain ikan, kerang dan sejenisnya (yang ada dilaut), diatas lautpun Allah telah menciptakan bahterabahtera atau kapal-kapal laut, ada yang bertenaga mesin, namun ada juga yang mengandalkan angin berarti kapal tersebut menggunakan layar untuk menahan angin dan hasilnya untuk mendorong kapal itu agar bergerak. Kapal-kapal tersebut dapat digunakan untuk mencari ikan yang dapat dijual dan kemudian mendapat uang yang dapat dimanfaatkan untuk membeli sesuatu yang dibutuhkan manusia, atau bisa juga kapal-kapal itu digunakan untuk mengangkut manusia atau binatang dari pulau yang satu kepulau yang lain. Semua itu Allah ciptakan untuk membuat manusia dapat melakukan segala sesuatu dengan mudah, sehingga manusia bisa menikmatinya dan semua itu merupakan salah satu tanda-tanda kebesaran dan kenikmatan Allah (Shihab, 2002).

Kebutuhan sarana transportasi umum merupakan salah satu kebutuhan masyarakat yang terus berkembang sejalan dengan makin meningkatnya taraf kehidupan ekonomi masyarakat. Adanya peningkatan kebutuhan sarana transportasi tidak lepas dari keinginan masyarakat untuk mendapatkan sarana transportasi yang baik dengan kriteria aman, cepat, murah, dan nyaman. Perubahan-perubahan selera yang terjadi dalam pemilihan jenis sarana angkutan tidak lepas pula dari adanya perkembangan sosial ekonomi masyarakat serta kemajuan teknologi (Sumarni, 2003).

Pertumbuhan ekonomi sangat berpengaruh bagi suatu daerah ataupun Negara karena menjadi salah satu acuan dalam membuat kebijakan. Pertumbuhan ekonomi lebih menunjukkan pada perubahan yang bersifat kuantitatif dan biasanya diukur dengan menggunakan data Produk Domestik Bruto. Sebagai salah satu sektor yang memiliki kontribusi penting dalam perekonomian nasional, sektor transportasi mampu memberi peran besar dalam perekonomian suatu Negara. Pengangkutan udara sangat berperan penting dalam pertumbuhan perekonomian dan meningkatkan kesejahteraan masyarakat (Gitosudarmo, 1998).

Transportasi udara mempunyai peran yang sangat penting bagi urat nadi kehidupan masyarakat, bangsa dan Negara. Sebagai pendukung dan pendorong pertumbuhan sektor-sektor lain serta pemicu pertumbuhan wilayah karena kelebihannya dalam kesepatan sehingga dinilai lebih efisien dalam 
Subbaniyah, et al/Jurnal Ekonomi Syariah Teori dan Terapan Vol. 4 No. 9 September 2017: 713-725; HUBUNGAN SEKTOR TRANSPORTASI DAN GROSS DOMESTIC PRODUCT (GDP) PADA NEGARA ANGGOTA ORGANISASI KERJASAMA ISLAM (OKI) DENGAN MENGGUNAKAN ANALISIS KAUSALITAS GRANGER TAHUN 1986-2015

penggunaannya.Transportasi udara yang saat ini diminati oleh masyarakat menjadikan pesawat sebagai sarana alat transportasi udara untuk berbagai keperluan. Transportasi udara yang lebih cepat dan efisien dibandingkan dengan transportasi darat dan laut menjadikan transportasi udara sebagai pilihan sarana transportasi yang semakin meningkat setiap tahunnya.

Semakin majunya alat transportasi membuat masyarakat semakin mudah untuk bepergian, transportasi udara merupakan pembangkit pengembangan potensi ekonomi karena kelebihannya dalam kecepatan sehingga dinilai lebih efisien dalam penggunaannya.Semakin meningkatnya transportasi yang dilakukan oleh masyarakat maka semakin meningkat pula pembangunan dan pertumbuhan ekonomi suatu Negara, intuisi ekonomi menunjukkan bahwa transportasi mungkin memiliki efek positif yang kuat pada pembangunan dan pertumbuhan ekonomi (Prasetya, 2014).

Dalam penelitian Beyzatlar, et al. (2014) disebutkan bahwa terdapat 3 saluran transportasi dapat berpengaruh secara positif terhadap perekonomian yaitu yang pertama adalah terdapat perbaikan dan pengembangan di transportasi dan terdapat peningkatan fasilitas serta meningkatkan keseluruhan unit produksi. Kedua, meningkatnya transportasi spillovers teknologi di seluruh Negara. Akhirnya, terjadi peningkatan profitabilitas tingkat mikro dengan hasil makro karena mengurangi biaya atau meningkatkan penjualan. Hal ini terjadi karena fasilitas transportasi memungkinkan perusahaan untuk mengakses input biaya terendah atau faktor produksi untuk kegiatan produksi mereka dan untuk mengakses pasar yang lebih luas dan mungkin dengan harga yang berpotensi lebih menguntungkan.

Penelitian ini memfokuskan analisis pada sektor penerbangan di negaranegara OKI. OKI merupakan organisasi negara-negara islam dan negara-negara yang mayoritas penduduknya beragam islam. Salah satu tujuan utama OKI adalah membentuk persatuan pada negaranegara Islam. Kerjasama dibidang ekonomi, politik, kebudayaan, dan ilmu pengetahuan. Kerjasama yang dilakukan bukan hanya pada sektor ekonomi saja tetapi juga kerja sama dalam bidang sosial budaya dan pertahanan. Dalam perkembangannya, distribusi penerbangan dalam hal ini juga digunakan sebagai pariwisata.

Perkembangan ekonomi di dalam negara anggota OKI belum sepenuhnya memuaskan, sebab angka perdagangan antar anggota masih sangat rendah bila dibandingkan dengan angka perdagangan dengan pihak luar, meskipun terdapat pengakuan terhadap potensi untuk pengembangan semacam pasaran bersama islam cukup besar karena semakin memiliki sumber daya alam yang melimpah, sejumlah negara anggota juga sudah cukup maju dibidang industri dan pengadaan sumber daya 
Subbaniyah, et al/Jurnal Ekonomi Syariah Teori dan Terapan Vol. 4 No. 9 September 2017: 713-725; HUBUNGAN SEKTOR TRANSPORTASI DAN GROSS DOMESTIC PRODUCT (GDP) PADA NEGARA ANGGOTA ORGANISASI KERJASAMA ISLAM (OKI) DENGAN MENGGUNAKAN ANALISIS KAUSALITAS GRANGER TAHUN 1986-2015

manusia (SDM) (Www.ekonomi.lipi.go.id, diakses pada 25 September 2016).

Penjelasan diatas menunjukkan bahwa terdapat keterkaitan antara sektor transportasi dengan kegiatan perekonomian yang terdapat dalam Negara Konferensi Islam (OKI) sangat besar karena semua aktifitas perekonomian sangat membutuhkan adanya dukungan dari sektor transportasi. Semakin lancarnya hubungan sektor transportasi dengan sektor-sektor ekonomi yang lain maka perekonomian suatu Negara akan semakin meningkat.

Sesuai dengan UU No.22 Tahun 2009 tentang lalu lintas dan angkutan jalan menjelaskan pengertian transportasi adalah pemindahan orang dan/ atau barang dari satu tempat ke tempat lain dengan menggunakan kendaraan. Menurut Gitosudarmo

mendefinisikan transportasi sebagai suatu proses pemindahan manusia atau barang dari satu tempat ke tempat lainnya menggunakan sebuah wahana yang digerakkan oleh manusia atau mesin.

Suatu sistem pasti membutuhkan suatu organisasi yaitu pengelola angkutan yang mengatur dan bekerja untuk menjamin bahwa suatu sistem tersebut berjalan dengan baik tanpa ada gangguan atau permasalahan didalamnya. Gitusudarmo (1998:45) menyatakan bahwa transportasi memiliki lima unsur, yakni manusia, barang, kendaraan, jalan, dan organisasi. Manusia
Berdasarkan uraian latar belakang di atas, rumusan masalah dalam penelitian ini adalah apakah terdapat hubungan timbal balik (Kausalitas Granger) antarvariabel Sektor Transportasi dan Gross Domestic Product (GDP) pada Negara anggota Organisasi Kerjasama Islam (OKI) pada tahun 1986-2015?

Adapun tujuan yang ingin dicapai dalam penelitian ini adalah Untuk mengetahui hubungan timbal balik (Kausalitas Granger) antara sektor transportasi dan Gross Domestic Product (GDP) pada Negara anggota Organisasi Kerjasama Islam (OKI).

\section{LANDASAN TEORI}

berperan sebagai pengguna jasa transportasi yang memanfaatkan moda transportasi untuk melakukan aktifitasnya, manusia juga berperan sebagai pengatur sistem transportasi agar dapat digunakan sesuai dengan fungsi dan manfaatnya.Barang menjadi objek pengangkutan, pengiriman barang kebeberapa tempat dengan alasan pemasaran namun juga mobilitas lalu lintas yang dimaksudkan untuk meningkatnya kesejahteraan manusia.Pada umumnya kegiatan transportasi memberikan dampak dalam kegiatan ekonomi suatu daerah.Besarnya manfaat ini sangat bergantung pada elastisitas produksi dalam biaya angkutan. Tambahan output dari kegiatan produksi tersebut dengan adanya jalan dikurangi dengan nilai sarana produksi merupakan benefit dari proyek tersebut. 
Subbaniyah, et al/Jurnal Ekonomi Syariah Teori dan Terapan Vol. 4 No. 9 September 2017: 713-725; HUBUNGAN SEKTOR TRANSPORTASI DAN GROSS DOMESTIC PRODUCT (GDP) PADA NEGARA ANGGOTA ORGANISASI KERJASAMA ISLAM (OKI) DENGAN MENGGUNAKAN ANALISIS KAUSALITAS GRANGER TAHUN 1986-2015

Pada zaman Rasulullah SAW unta biasanya digunakan sebagai kendaraan termasuk perang.Tenaganya yang kuat dengan berjalan di tengah gurun pasir menjadi nilai positif dari hewan tersebut. Meskipun demikian, hewan tersebut tidak bisa berlari kencang seperti kuda. Namun, pada saat itu alat transportasi utama antar wilayah atau kota adalah kuda, unta, keledai, dan kereta kuda. Manusia menempuh jarak yang jauh dengan berjalan kaki, bagi yang mampu tentunya mengendarai kuda atau kereta kuda.Dalam hal tersebut, binatangbinatang tunggangan serta alat-alat pengangkutan umum lainnya merupakan kendaraan yang memang diciptakan Allah untuk manusia agar dapat mereka kendarai. Terdapat dalam surat Yasin 36:41-42 sebagai berikut:

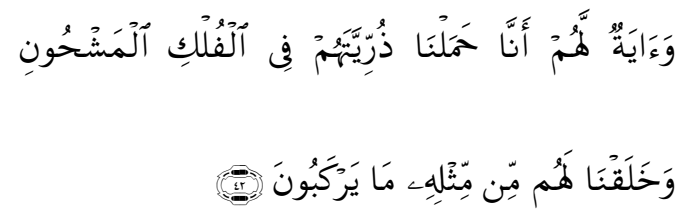

Wa-Éyatul'lahum AnnÉ HamalnÉÚurrÊyyahum Fi'lfulki'l-MasyhËm.WaKhalaqnÉ Lahum'mim'miîlihi MÉ YarkabËn.

Artinya: "Dan suatu tanda (kebesaran Allah) bagi mereka bahwa Kami angkut keturunan mereka dalam perahu yang penuh muatan. Dan kami ciptakan bagi mereka dari yang semacam itu, yang dapat mereka pergunakan di daratan (hewanhewan untuk dikendarai)." (Q.S 36:4142, Departemen Agama RI. 2013:444)
Dalam surat ini dijelaskan tandatanda kebesaran Allah nikmat yang diberikan kepada manusia adalah diajarkan cara membuat kapal, Karen yang pertama kali membuat kapal adalah Nabi Nuh, berapa banyak manfaat yang telah diambil dengan adanya kapal yang bisa membawah manusia dan bisa berlayar dengan tenang, dan juga manusia bisa membuat semacam kendaraan yang bisa di kendarai di daratan seperti halnya motor, mobil, kereta api dll.

Seiring dengan perkembangan jaman, yang mana semua transportasi mengalami peningkatan yang sangat pesat salah satunya transportasi darat. Kebutuhan manusia sekarang pun sudah merujuk pada penggunaan alat transportasi yang dapat beroperasi dalam jangka waktu yang singkat yang mampu mengantarkan mereka ke tempat tujuan dengan cepat dan efektif. Beberapa tahun belakangan ini pesawat merupakan alternative terbaik yang menjadi pilihan masyarakat sebagai alat transportasi luar kota maupun luar negeri. Transportasi udara telah menjadi bagian penting manusia, kebutuhan terhadap transportasi ini digunakan untuk memajukan berbagai aspek kehidupan seperti perdagangan, pendidikan, industri, maupun aspek sosial.

Transportasi udara merupakan pembangkit pengembangan ekonomi karena kelebihannya dalam kecepatan sehingga dinilai lebih efisien dalam penggunaannya. Hal ini terlihat dari 
Subbaniyah, et al/Jurnal Ekonomi Syariah Teori dan Terapan Vol. 4 No. 9 September 2017: 713-725; HUBUNGAN SEKTOR TRANSPORTASI DAN GROSS DOMESTIC PRODUCT (GDP) PADA NEGARA ANGGOTA ORGANISASI KERJASAMA ISLAM (OKI) DENGAN MENGGUNAKAN ANALISIS KAUSALITAS GRANGER TAHUN 1986-2015

jumlah penumpang dan jumlah penerbangannya, dapat diketahui bahwa jumlah penumpang internasional dan domestic yang menggunakan jasa angkutan udara meningkat dalam 10 tahun terakhir. Meningkatnya jumlah penumpang dan jumlah penerbangan moda transportasi udara merupakan salah satu indicator yang menunjukkan peningkatan taraf perekonomian masyarakat.

Pertumbuhan ekonomi merupakan perkembangan kegiatan dalam perekonomian yang menyebabkan barang dan jasa yang diproduksi dalam masyarakat bertambah dan kemakmuran masyarakat menjadi meningkat. Dari satu periode lainnya kemampuan suatu Negara untuk menghasilkan barang dan jasa akan semakin meningkat. Hal ini disebabkan karena faktor produksi akan selalu mengalami pertambahan dalam jumlah dan kualitasnya. Investasi menambah modal, teknologi yang dipergunakan menjadi berkembang dan juga tenaga kerja akan bertambah sebagai akibat perkembangan penduduk (Siregar, 2010:1).

\section{Hipotesis}

$\mathrm{H} 1$ : Terdapat hubungan timbal balik (dua arah) antara sektor transportasi dan Gross Domestic Prodact (GDP) pada Negara anggota OKI tahun 19862015.

\section{Model Analisis}

III. METODE PENELITIAN

Pendekatan Penelitian
Menurut Mankiw (2000:15-16) Salah satu indicator untuk mengukur pertumbuhan ekonomi secara makro yaitu dengan menggunakan nilai Produk Domestik Bruto (PDB). PDB merupakan nilai total pendapatan dan pengeluaran barang dan jasa yang diproduksi suatu Negara atau diproduksi secara domestic dalam suatu perekonomian selama kurun waktu tertentu. PDB sering dianggap sebagai indicator terbaik dari kinerja perekonomian.

Pertumbuhan ekonomi yang tinggi hal yang sangat diinginkan semua Negara. Pertumbuhan ekonomi mencerminkan kegiatan ekonomi yang dapat bernilai positif dan bahkan dapat pula bernilai negative. Pada satu periode perekonomian mengalami pertumbuhan yang positif, maka kegiatan ekonomi pada periode tersebut mengalami peningkatan, tetapi jika pada suatu periode perekonomian menglami pertumbuhan yang negative, berarti kegiatan ekonomi pada periode tersebut mengalami penurunan.

\section{Gambar 1}

\section{Model Analisis Sektor Transportasi dan GDP Negara OKI}

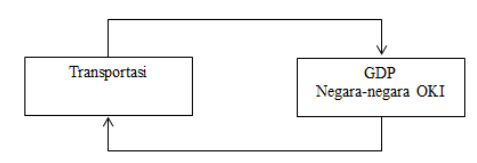

Sumber : Data Diolah 
Subbaniyah, et al/Jurnal Ekonomi Syariah Teori dan Terapan Vol. 4 No. 9 September 2017: 713-725; HUBUNGAN SEKTOR TRANSPORTASI DAN GROSS DOMESTIC PRODUCT (GDP) PADA NEGARA ANGGOTA ORGANISASI KERJASAMA ISLAM (OKI) DENGAN MENGGUNAKAN ANALISIS KAUSALITAS GRANGER TAHUN 1986-2015

Pendekatan kuantitatif menurut Anshori dan Irawati (2009:13) merupakan pendekatan kuantitatif untuk menjawab masalah yang telah dirumuskan sebelumnya dan memerlukan perhitungan yang bersifat matematis dengan menggunakan rumus statistik tertentu.

\section{Indentifikasi Variabel}

Untuk menjawab rumusan masalah dan menguji hipotesis, maka variabel independen dan variabel dependen yang digunakan dalam penelitian ini adalah sektor transportasi dan Gross Domestic Product (GDP). Dimana variabel dependen (variabel tidak bebas) dapat dipengaruhi variabel independen (variabel bebas) dan disisi lain variabel independen tersebut dapat menempati posisi variabel dependen.

\section{Definisi Operasional}

Untuk memberikan gambaran yang jelas mengenai variabel yang digunakan dalam penelitian ini, maka variabel tersebut dapat didefinisikan sebagai berikut:

1. Transportasi didefinisikan secara operasional sebagai suatu jasa yang diberikan guna menolong orang dan barang atau suatu usaha dan kegiatan mengangkut atau membawah barang dan/atau penumpang dari suatu Negara-negara anggota OKI pada tahun 1986-2015.

2. Gross Domestic Product (GDP) didefinisikan secara operasional sebagai nilai pasar dari semua barang dan jasa akhir yang diproduksi oleh Negara-negara anggota OKI pada tahun 19862015.

\section{Jenis dan Sumber Data}

Dalam penelitian ini, keseluruhan datanya adalah data sekunder yang diperoleh dari situs resmi World Bank (Bank Dunia) yakni www.worldbank.org, yang meliputi laporan tahunan data transportasi udara dan Gross Domestic Product (GDP) yang dipublis sesuai tahun penelitian.

\section{Populasi dan Sampel}

Populais yang digunakan dalam penelitian ini adalah seluruh Negara anggota Organisasi Kerjasama Islam (OKI).Teknik pengambilan sampel dalam penelitian ini menggunakan teknik purposive sampling.Dimana dalam penelitian ini sampel yang digunakan adalah Negara-negara anggota OKI yang memiliki nilai GDP dan sektor transportasi pada tahun 1986-2015 yakni sejumlah 15 negara.

\section{Teknik Analisis Data}

Teknik analisis data yang digunakan dalam penelitian ini adalah kausalitas granger, dengan pemilihan model estimasi uji stasioner (unit root test), penentuan lag optimum, dan uji kausalitas granger. Data stasioner merupakan salah satu prasyarat dalam model ekonometrika untuk data time series, data stasioner merupakan pengujian untuk mengetahui stasioneritas data dengan menggunakan 
Subbaniyah, et al/Jurnal Ekonomi Syariah Teori dan Terapan Vol. 4 No. 9 September 2017: 713-725; HUBUNGAN SEKTOR TRANSPORTASI DAN GROSS DOMESTIC PRODUCT (GDP) PADA NEGARA ANGGOTA ORGANISASI KERJASAMA ISLAM (OKI) DENGAN MENGGUNAKAN ANALISIS KAUSALITAS GRANGER TAHUN 1986-2015

uji Augmented Dickey-Fuller (ADF) test, dengan melihat nilai probabilitas sebesar 0.0001 lebih kecil dari a $(0,01)$ jika data tidak stasioner pada order nol (lo), maka stasioneritas data tersebut bisa dilihat dari order berikutnya yaitu firstdifference atau I, atau second difference $I_{2}$.

Penentuan Lag optimum dapat dilakukan dengan menggunakan kriteria informasi yang tersedia. Kandidat lag yang dipilih adalah panjang lag menurut kriteria Schwartz Iformation Criterion (SIC), lag optimum merupakan cara untuk memilih seberapa besar jumlah lag yang digunakan dalam penelitian sebelum melakukan uji granger causality, sehingga pemilihan jumlah lag optimum sangat digunakan agar memperoleh hasil yang lebih baik.

Uji Kauslaitas granger antar variabel penelitian dimaksudkan untuk mengetahui dan membuktikan arah hubungan antar variabel, sehingga dapat diketahui pola hubungan antar variabel, dapat berupa hubungan kausalitas dua arah atau hanya satu berlaku satu arab atau tidak ada hubungan sama keduanya. Pengujian kausalitas granger dilihat dari probabilitas kurang dari 0.01 artinya variabel yang diteliti memiliki hubungan kausalitas jika 0.0001 lebih kecil dari 0.01 .

\section{Hasil dan Pembahasan}

Tahap pengujian pertama yang dilakukan dalam penelitian ini adalah uji stasioneritas data yang mana dilakukan menggunakan uji akar (unit root test), uji akar unit root test yang menggunakan
Augmented Diskey Fuller (ADF) statistic untuk kurun waktu 1986-2015. Berikut ini adalah hasil estimasi dari uji ADFGross Domestic Product (GDP) dan sektor transportasi:

\section{Tabel 1}

Hasil Pengujian ADF Sektor Transportasi dan Gross Domestic Product (GDP)

\begin{tabular}{|l|l|l|l|}
\hline \multicolumn{5}{|c|}{ Uji Akar Unit Variabel Sektor Transportasi } \\
\hline \multicolumn{1}{|c|}{ Negara } & \multicolumn{1}{c|}{ ADF } & \multicolumn{1}{c|}{ Critical Value } & \multicolumn{1}{c|}{ Derajat Integrasi } \\
\hline Bangladesh & -8.595479 & $0.0000^{*}$ & $1^{\text {st }}$ difference \\
\hline Brunei Darussalam & -4.787910 & $0.0034^{*}$ & $1^{\text {st }}$ difference \\
\hline Egypt, Arab Rep & -9.292707 & $0.0000^{*}$ & $2^{\text {nd }}$ difference \\
\hline Indonesia & -4.968899 & $0.0022^{*}$ & $1^{\text {st }}$ difference \\
\hline Jordan & -6.799227 & $0.0000^{*}$ & $2^{\text {nd }}$ difference \\
\hline Malaysia & -6.204082 & $0.0001^{*}$ & $1^{\text {st }}$ difference \\
\hline Maroko & -4.218008 & $0.0173^{* *}$ & $2^{\text {nd }}$ difference \\
\hline Mozambik & -6.918283 & $0.0000^{*}$ & $2^{\text {nd }}$ difference \\
\hline Pakistan & -5.800945 & $0.0003^{*}$ & $1^{\text {st }}$ difference \\
\hline Saudi Arabia & -6.845656 & $0.0000^{*}$ & $1^{\text {st }}$ difference \\
\hline Sudan & -5.552566 & $0.0006^{*}$ & $1^{\text {st difference }}$ \\
\hline Suriname & -8.703969 & $0.0000^{*}$ & $1^{\text {st }}$ difference \\
\hline Tunisia & -7.709833 & $0.0000^{*}$ & $1^{\text {st }}$ difference \\
\hline Turki & -4.826735 & $0.0031^{*}$ & $1^{\text {st }}$ difference \\
\hline Uganda & -4.359381 & $0.0092^{*}$ & $1^{\text {st }}$ difference \\
\hline $\begin{array}{l}\text { Keterangan : } \\
* \\
=\end{array}$ Signifikan pada $\alpha=1 \%$ & & \\
$* * *$ Signifikan pada $\alpha=5 \%$ & & \\
$* * *$ & $=$ Signifikan pada $\alpha=10 \%$ & & \\
\hline
\end{tabular}

\begin{tabular}{|c|c|c|c|}
\hline \multicolumn{4}{|c|}{ Uji Akar Unit Variabel Gross Domestic Product (GDP) } \\
\hline Negara & $\mathrm{ADF}$ & Critical Value & Derajat Integrasi \\
\hline Bangladesh & -4.213866 & $0.0128 *$ & $1^{\text {st }}$ difference \\
\hline Brunei Darussalam & -5.015651 & $0.0021^{*}$ & $1^{\text {st }}$ difference \\
\hline Egypt, Arab Rep & -4.971188 & $0.0033^{*}$ & $2^{\text {nd }}$ difference \\
\hline Indonesia & -3.623536 & $0.0458 * *$ & $1^{\text {st }}$ difference \\
\hline Jordan & -7.662913 & $0.0000^{*}$ & $2^{\text {nd }}$ difference \\
\hline Malaysia & -5.049082 & $0.0018^{*}$ & $1^{\text {st }}$ difference \\
\hline Maroko & -4.038227 & $0.0245^{* *}$ & $2^{\text {nd }}$ difference \\
\hline Mozambik & -6.064891 & $0.0005^{*}$ & $2^{\text {nd difference }}$ \\
\hline Pakistan & -3.277557 & $0.0940^{* * *}$ & $1^{\text {st }}$ difference \\
\hline Saudi Arabia & -5.415035 & $0.0008^{*}$ & $1^{\text {st }}$ difference \\
\hline Sudan & -7.070821 & $0.0000^{*}$ & $1^{\text {st }}$ difference \\
\hline Suriname & -6.543176 & $0.0000^{*}$ & $1^{\text {st }}$ difference \\
\hline Tunisia & -4.607017 & $0.0052^{*}$ & $1^{\text {st }}$ difference \\
\hline Turki & -6.080105 & $0.0002^{*}$ & $1^{\text {st }}$ difference \\
\hline Uganda & -4.709518 & $0.0041^{*}$ & $1^{\text {st }}$ difference \\
\hline $\begin{array}{l}\text { Keterangan : } \\
\begin{aligned} * & =\text { Signifikan pa } \\
* * & =\text { Signifikan p } \\
* * * & =\text { Signifikan pa }\end{aligned}\end{array}$ & $\begin{array}{l}\alpha=1 \% \\
\alpha=5 \% \\
\alpha=10 \%\end{array}$ & & \\
\hline
\end{tabular}

Sumber: hasil olah data

Dari hasil olah data pada tabel 1 diatas dilihat bahwa hasil uji akar unit untuk variabel Gross Domestic Product (GDP) dan sektor transportasi pada 11 negara anggota OKI stasioner pada integrasi latau First Difference yaitu 
Subbaniyah, et al/Jurnal Ekonomi Syariah Teori dan Terapan Vol. 4 No. 9 September 2017: 713-725; HUBUNGAN SEKTOR TRANSPORTASI DAN GROSS DOMESTIC PRODUCT (GDP) PADA NEGARA ANGGOTA ORGANISASI KERJASAMA ISLAM (OKI) DENGAN MENGGUNAKAN ANALISIS KAUSALITAS GRANGER TAHUN 1986-2015

Negara Bangladesh, Brunei Darussalam, Indonesia, Malaysia, Pakistan, Saudi Arabia, Sudan, Suriname, Tunisia, Turki, dan Uganda. Sedangkan 4 negara lainnya stasioner pada derajat integrasi 2 Difference yaitu Egypt, Arab Rep, Jordan, Maroko, dan Mozambik.

Uji yang kedua menggunakan penentuan lag optimum, yang mana digunakan untuk memilih seberapa besar jumlah lag yang digunakan dalam penelitian sebelum melakukan uji kausalitas granger, sehingga pemilihan jumlah lag optimum sangat diperlukan agar memperoleh hasil yang lebih baik. Hasil penentuan lag ptimum pada 15 negara anggota OKI yaitu:

Tabel 2 Hasil Uji Panjang Lag Optimum

\begin{tabular}{|l|c|}
\hline \multicolumn{1}{|c|}{ Negara } & Lag \\
\hline Bangladesh & 1 \\
\hline Brunei Darussalam & 1 \\
\hline Egypt, Arab Rep & 2 \\
\hline Indonesia & 1 \\
\hline Jordan & 1 \\
\hline Malaysia & 1 \\
\hline Maroko & 2 \\
\hline Mozambik & 1 \\
\hline Pakistan & 1 \\
\hline Saudi Arabia & 1 \\
\hline Sudan & 1 \\
\hline Suriname & 1 \\
\hline Tunisia & 2 \\
\hline Turki & 1 \\
\hline Uganda & 1 \\
\hline Sumber: hasil olah data
\end{tabular}

Sumber: hasil olah data

Penentuan Lag Optimal menggunakan kriteria-kriteria, seperti Final Prediction Error (FPE), Akaike Information Critirion (AIC), Schawrz Information (SIC),
Hannan-Quinn Information Critirion (HQ). Dari hasil pengujian Lag Optimal dengan menggunaka eviews 7 , ditemukan bahwa berdasarkan tiga kriteria yang terdapat tanda * paling banyak menunjukkan hasil pada Lag 1 yaitu Negara Bangladesh, Brunei Darussalam,Indonesia, Jordan, Malaysia, Mozambik, Pakistan, Saudi Arabia, Sudan, Suriname, Turki dan Uganda. Pada Lag 2 yaitu Negara Egypt Arab Rep, Pakistan dan Tunisia.

Uji selanjutnya yaitu uji kausalitas granger antar variabel penelitian dimaksudkan untuk mengetahui dan membuktikan arah hubungan antar variabel, sehingga dapat diketahui pola hubungan antar variabel, dapat berupa hubungan kausalitas dua arah atau hanya berlaku hubungan satu arah atau tidak ada hubungan sama keduanya. Pengujian kausalitas granger jika nilai probabilitas kurang dari 0.01 artinya variabel yang diteliti memiliki hubungan kausalitas. Hasil pengujian kausalitas granger yaitu: 
Tabel 3

Hasil Uji Kausalitas Granger

\begin{tabular}{|c|c|c|c|}
\hline Negara & $\begin{array}{c}\text { Hubungan Antar } \\
\text { Variabel }\end{array}$ & Probabilitas & Keterangan \\
\hline Bangladeah & $\begin{array}{l}\text { LNGDP - LNTRA } \\
\text { LNTRA - LNGDP }\end{array}$ & $\begin{array}{l}0.7797 \\
0.4926\end{array}$ & $\begin{array}{l}\text { Dalam Negara ini } \\
\text { tidak ada hubungan } \\
\text { kasusalitas antar } \\
\text { kedua variabel. }\end{array}$ \\
\hline Brumei Darussalam & $\begin{array}{l}\text { LNGDP - LNTRA } \\
\text { LNTRA - LNGDP }\end{array}$ & $\begin{array}{l}0.3275 \\
0.5108\end{array}$ & $\begin{array}{l}\text { Dalam Negara ini } \\
\text { tidak ada hubungan } \\
\text { ksusalitas antar } \\
\text { kadua variabel. }\end{array}$ \\
\hline Egypt, Arab Rep & $\begin{array}{l}\text { LNGDP - LNTRA } \\
\text { LNTRA - LNGDP }\end{array}$ & $\begin{array}{l}0.0800 \\
0.6141\end{array}$ & $\begin{array}{l}\text { Terdapst hubungan } \\
\text { kausalitas satu arah } \\
\text { antara LNGDP ke } \\
\text { LNTRA. }\end{array}$ \\
\hline Indonesia & $\begin{array}{l}\text { LNGDP - LNTRA } \\
\text { LNTRA - LNGDP }\end{array}$ & $\begin{array}{l}0.6403 \\
0.8665\end{array}$ & $\begin{array}{l}\text { Dalam Negara ini } \\
\text { tidak ada hubungan } \\
\text { kasusalitas antar } \\
\text { kedua variabel. }\end{array}$ \\
\hline Jordan & $\begin{array}{l}\text { LNGDP - LNTRA } \\
\text { LNTRA - LNGDP }\end{array}$ & $\begin{array}{l}0.2777 \\
0.9442\end{array}$ & $\begin{array}{l}\text { Dalam Negara ini } \\
\text { tidak ads hubungan } \\
\text { kausalitas antar } \\
\text { kadua variabel. }\end{array}$ \\
\hline Malsysia & $\begin{array}{l}\text { LNGDP - LNTRA } \\
\text { LNTRA - LNGDP }\end{array}$ & $\begin{array}{l}0.8644 \\
0.8266\end{array}$ & $\begin{array}{l}\text { Dalam Negara ini } \\
\text { tidak ada hubungan } \\
\text { ksusalitas antar } \\
\text { kadua variabel. }\end{array}$ \\
\hline Maroko & $\begin{array}{l}\text { LNGDP - LNTRA } \\
\text { LNTRA - LNGDP }\end{array}$ & $\begin{array}{l}0.8554 \\
0.7819\end{array}$ & $\begin{array}{l}\text { Dalam Negara ini } \\
\text { tidalk ada hubungan } \\
\text { kasualitas antar } \\
\text { kedua variabel. }\end{array}$ \\
\hline Mozambik & $\begin{array}{l}\text { LNGDP - LNTRA } \\
\text { LNTRA - LNGDP }\end{array}$ & $\begin{array}{l}0.0938 \\
0.0031\end{array}$ & $\begin{array}{l}\text { Terdapat hubungan } \\
\text { ksusalitas dua arah } \\
\text { antara LNGDP ke } \\
\text { LNTRA dan } \\
\text { sabalinya. }\end{array}$ \\
\hline Pakistan & $\begin{array}{l}\text { LNGDP - LNTRA } \\
\text { LNTRA - LNGDP }\end{array}$ & $\begin{array}{l}0.0127 \\
0.4035\end{array}$ & $\begin{array}{l}\text { Terdispat hubungan } \\
\text { kasusalitas satu arah } \\
\text { antara LNGDP ke } \\
\text { LNTRA. }\end{array}$ \\
\hline Ssudi Arabia & $\begin{array}{l}\text { LNGDP - LNTRA } \\
\text { LNTRA - LNGDP }\end{array}$ & $\begin{array}{l}0.0458 \\
0.1507\end{array}$ & $\begin{array}{l}\text { Terdapat hubungan } \\
\text { ksusalitas satu arah } \\
\text { antara LNGDP ke } \\
\text { LNTRA. }\end{array}$ \\
\hline
\end{tabular}

\begin{tabular}{|c|c|c|c|}
\hline Negara & $\begin{array}{c}\text { Hubungan Antar } \\
\text { Variabel }\end{array}$ & Probabilitas & Keterangan \\
\hline Sudan & $\begin{array}{l}\text { LNGDP-LNIRA } \\
\text { LNTRA-LNGDP }\end{array}$ & $\begin{array}{l}0.2571 \\
0.6890\end{array}$ & $\begin{array}{l}\text { Dalsm Negara ini } \\
\text { tidak sda hubungan } \\
\text { kausalitas antrs } \\
\text { kedua variabel. }\end{array}$ \\
\hline Suringme & $\begin{array}{l}\text { LNGDP -LNTRA } \\
\text { LNIRA-LNGDP }\end{array}$ & $\begin{array}{l}0.5180 \\
0.1690\end{array}$ & $\begin{array}{l}\text { Dalam Negara ini } \\
\text { tidak ads hubungan } \\
\text { kasualitas antar } \\
\text { kedua variabel. }\end{array}$ \\
\hline Tunisia & $\begin{array}{l}\text { LNGDP-LNTRA } \\
\text { LNTRA-LNGDP }\end{array}$ & $\begin{array}{l}0.0378 \\
0.0177\end{array}$ & 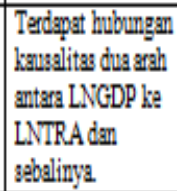 \\
\hline Turki & $\begin{array}{l}\text { LNGDP-LNTRA } \\
\text { LNTRA-LNGDP }\end{array}$ & $\begin{array}{l}0.1133 \\
0.1201\end{array}$ & $\begin{array}{l}\text { Dalam Negara ini } \\
\text { tidal ads hubungan } \\
\text { kausalitss antar } \\
\text { keshua variabel. }\end{array}$ \\
\hline Ugands & $\begin{array}{l}\text { LNGDP -LNTRA } \\
\text { LNTRA-LNGDP }\end{array}$ & $\begin{array}{l}0.3321 \\
0.7228\end{array}$ & $\begin{array}{l}\text { Dalsm Neggra ini } \\
\text { tidal sda hubungar } \\
\text { kausalitas antar } \\
\text { kedua variabel. }\end{array}$ \\
\hline
\end{tabular}

Sumber: hasil olah data

Dari olah data di atas yang memiliki hubungan timbal balik dua arah antara sektor transportasi dan Gross Domestic Product (GDP) adalah Negara mozambik dan Tunisia. Di Negara Mozambik dan Tunisia terdapat hubungan dua arah antara GDP dan sektor transportasi bahwa semakin maju tingkat kegiatan perekonomian suatu Negara, maka transportasi akan memainkan peran yang besar sebagai penunjang pembangunan, dan sektor transportasi juga berpengaruh terhadap GDP bahwa pemerintah melakukan berbagai cara agar pendapatan Negara bisa meningkat dengan kualitas dari fasilitas, infrakstruktur, kelembagaan, sarana dan prasarana yang semakin di perbaiki agar bisa meningkatkan pendapatan Negara.

Transportasi infrakstruktur sebagai biaya mengurangi teknologi, tetapi perbaikan dalam infrakstruktur transportasi memungkinkan spesialisasi dan pertumbuhan jangka panjang. Biaya mengurangi teknologi dibidang infrakstruktur membuat produksi input lebih efisien disbandingkan dengan dampaknya pada efisiensi dalam produksi barang akhir hal ini dapat meningkatkan pendapatan (Bougheas et al, 2000)

Tedapat dalam firman Allah Surat AlIsra' 17:70 sebagai berikut:

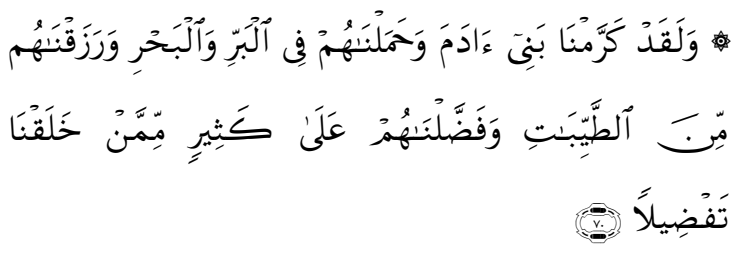

Walaqad Kar-ramnÉ BanÊ'Ódama WaÍamalnÉhum FÊ'l-Lbahri Wa-RaZa'q-QnÉhum'm-mina'l-LÙayibÉti WafaİalnÉhum 'alÉ KâTiri'm-mimman KholaqnÉ Tafìilé.

Artinya: "Dan sesungguhnya telah kami muliakan anak cucu adam, dan kami angkut mereka di daratan dan 
Subbaniyah, et al/Jurnal Ekonomi Syariah Teori dan Terapan Vol. 4 No. 9 September 2017: 713-725; HUBUNGAN SEKTOR TRANSPORTASI DAN GROSS DOMESTIC PRODUCT (GDP) PADA NEGARA ANGGOTA ORGANISASI KERJASAMA ISLAM (OKI) DENGAN MENGGUNAKAN ANALISIS KAUSALITAS GRANGER TAHUN 1986-2015

dilautan, dan kami beri mereka rezeki dari yang baik-baik dan kami lebihkan mereka atas banyak dari siapa yang telah kami ciptakan, dengan kelebihan yang sempurna" (Q.S 17:70. Departemen Agama Rl, 2002).

Menurut tafsit oleh Shihab, vol. 7 (2009:149-152) menjelaskan bahwa Allah telah menyempurnakan manusia dengan bentuk tubuh yang bagus, kemampuan berbicara dan berfikir, serta berpengetahuan serta diberi kebebasan memilah dan memilih.Dengan aneka transportasi yang diciptakan dan ditundukkan bagi manusia yang sesuai dengan kebutuhan dan manfaat untuk pertumbuhan fisik dan perkembangan jiwa manusia, yang telah dilebihkan dari hewan dengan akal dan daya cipta sehingga menjadi manusia yang bertanggung jawab.Serta Allah memberikan kepada manusia rezeki dan manusia dianugerahi Allah keistimewaan yang tidak dianugerahkan-Nya kepada selain manusia.

Maksud dari ayat di atas adalah Allah telah menciptakan manusia dengan keistimewaan melebihi selain manusia, dengan aneka transportasi yang diberikan oleh Allah kepada manusia yang bis digunakan sebagai kebutuhan dan manfaat untuk pertumbuhan hidupnya. Dan Allah memberi Rezeki bagi manusia yang baik yang sesuai dengan kebutuhan manusia yang bermanfaat.

Perekonomian Mozambik dan Tunisia telah berkembang sama-sama mengandalkan dari sektor industry, kemudian pertanian. Sektor pariwisata menjadi salah satu sektor penyumbang penerimaan Negara, dengan semakin banyaknya pengunjung pariwisata akan memberikan pemasukan pada sektor lain, salah satunya transportasi udara.

Negara yang hanya memiliki hubungan searah adalah Egypt, Arab Rep, Pakistan, dan Saudi Arabia.Transportasi mempunyai pengaruh besar terhadap perorangan, masyarakat, pembangunan, ekonomi, dan social politik suatu Negara. Pengangkutan merupakan sarana dan prasarana bagi pembangunan ekonomi Negara yang bisa mendorong lajunya pertumbuhan ekonomi (Rate Of Growt) (Salim, 2002:10).

Terdapat dalam Surat An-Nahl 16:8 sebagai berikut:

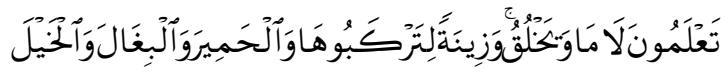

Wa'l-Khoi-la Wa-lbighÉla Wa'lÍamÊra LitarkabËhÉ WazÊEnah N Wayakhluqu MÉ LÉ Ta'lamën.

Artinya: "Dan (dia telah menciptakan) kuda, bagal, dan keledai, agar kamu menungganginya dan (menjadikannya) perhiasan. Dan Allah menciptakan apa yang kamu tidak mengetahuinya." (Q.S 16:8, Departemen Agama RI. 2013:268)

Didalam surat tersebut dijelaskan bahwa Allah menciptakan untuk hambahNya serta menganugerahkan kepada 
Subbaniyah, et al/Jurnal Ekonomi Syariah Teori dan Terapan Vol. 4 No. 9 September 2017: 713-725; HUBUNGAN SEKTOR TRANSPORTASI DAN GROSS DOMESTIC PRODUCT (GDP) PADA NEGARA ANGGOTA ORGANISASI KERJASAMA ISLAM (OKI) DENGAN MENGGUNAKAN ANALISIS KAUSALITAS GRANGER TAHUN 1986-2015

mereka berupa kuda, bagal, dan keledai yang Allah jadikan sebagai tunggangan dan perhiasan dan itu semua adalah tujuan yang paing besar. Dan ketika Allah merinci binatang-binatang ini dan menyebutkannya secara terpisah dari binatang-binatang ternak, sebagian ulama menjadikan hal itu sebagai dalil atas pendapatan mereka bahwa daging kuda adalah haram, bahwa sesungguhnya Allah menyebutnya bersama dengan bagal dan keledai yang memang kedua-duanya adalah haram.tetapi binatang ini digunakan sebagai binatang tunggangan. pada masa Rasulullah Nabi menggunakan kuda sebagai tumpangan pada saat peperangan, dan Rasulullah juga perna dihadiahi seekor bagal dan waktu itu Rasulullah menungganginya.

Pendapatan tumbuh dikarenakan oleh kemajuan teknologi, hal ini memungkinkan permintaan umum meningkat dan mengarahkan pada perkembangan sektor jasa.Transportasi merupakan komponen penting dari sektor jasa, pembangunan ekonomi juga memiliki efek positif yang kuat pada transportasi (Eichengreen dan Gupta, 2013).

Negara Egypt, Arab Rep sangat tergantung pada pertanian, peternakan, pertambangan, perindustrian, perdagangan, dan pariwisata / transportasi. Negara Mesir dan Saudi Arabia sama-sama memiliki pendapatan terbesar dari sektor minyak Bumi, perekonomian Saudi Arabia dikenal dengan kekayaan yang sangat besar yang didapat dari minyak yang sangat membantu kekuatan peran dari kerajaan Saudi baik di dalam maupun diluar negeri.

Sektor jasa memiliki pengaruh yang besar dalam pendapatan Negara Pakistan, pada sektor transportasi udara juga menjadi salah satu menyumbang GDP terbesar Negara Pakistan, meskipun Cuma terdapat satu bandara tetapi Internasional Airlines milik Negara Pakistan adalah pembawah udara utama dan mendominasi sekitar $73 \%$ penumpang domestic dan semua barang dalam negeri.

Sedangkan Negara Mesir dan Saudi Arabia salah satu pendapatan terbesar di dapat dari sektor transportasi yang samasama didukung dari sektor pariwisata, mesir di dpaat dari pariwisata dan ekspor import barang, sedangkan Saudi Arabia salah satu penerimaan transportais terbesar di dapat dari ibadah haji, biaya untuk ibadah haji menjadi sumber devisa Negara Saudi, dengan banyaknya umat islam yang berkunjung ke kota Makkah maka dapat dipastikan dapat membawah dampak positif dalam perkembangan ekonomi Saudi Arabia.

\section{SIMPULAN}

Berdasarkan analisis hasil dan pembahasan dalam penelitian ini, maka dapat disimpulkan bahwa terdapat hubungan timbal balik (Kausalitas Granger) antara sektor transportasi dan GDP di 2 Negara anggota OKI yaitu Negara Mozambik dan Tunisia. Tetapi juga, terdapat hubungan satu arah 
Subbaniyah, et al/Jurnal Ekonomi Syariah Teori dan Terapan Vol. 4 No. 9 September 2017: 713-725; HUBUNGAN SEKTOR TRANSPORTASI DAN GROSS DOMESTIC PRODUCT (GDP) PADA NEGARA ANGGOTA ORGANISASI KERJASAMA ISLAM (OKI) DENGAN MENGGUNAKAN ANALISIS KAUSALITAS GRANGER TAHUN 1986-2015

antara GDP dan sektor transportasi di 3 negara anggota OKI yaitu pada Negara Egypt, Arab Rep, Pakistan, dan Saudi Arabia. Dari 15 negara anggota OKI tersebut yang tidak menjadikan sektor transportasi sebagai penyumbang penerimaan Negara.Penerimaan Negara terbesar rata-rata di dapat dari sektor pertanian, pertambangan, dan manufaktur.

\section{DAFTAR PUSTAKA}

Anshori, Muslich \& Sri Iswati. 2009. Buku Ajar Metodologi Penelitian Kuantitatif. Surabaya: Airlangga University Press.

Bank Dunia. 2016. Gross Domestic Product Per Capita. Tahun 1960-2016. Amerika Serikat: World Bank.

Beyzatlar, Mehmet Aldonat, dkk. 2014. Granger-causality between transportation and GDP: A panel. Jurnal Transpotation Research Part A.

Bougheas, S., Demetriade, P.O., Mamuneas, T.P., 2000. Infrastructure, Specialization, and Economic Growth. Canadian Jurnal Econ. Revenue Canadienned' Economique 33 (2), 506522.

Departemen Agama Rl, 2002. Al-Qur'an Terjemahan Indonesia. Jakarta: PT. Sari Agung.

Eichengreen, B., Gupta, P., 2013. The Two Wave OF Service-Sector Growth. Oxford Econ. Pap. 65, 96-123.

Gitusodarmo, Indriyo. 1998. Manajemen Sumber Daya Manusia. Jakarta: Ghaila Indonesia.

Irawati, Mei. 2012. Peranan Sektor Transportasi Dalam Perekonomian Indonesia. Skripsi tidak diterbitkan. Fakultas Ekonomi dan Bisnis Universitas Airlangga Surabaya.

Lembaga Ilmu Pengetahuan Indonesia. 2015. Revitasi Kerjasama Ekonomi Indonesia dengan Negara-Negara Anggota Organisasi Konferensi Islam (OKI).

(http://www.ekonomi.lipi.go.id/id/book /revitalisasi-kerjasama-ekonomiindonesia-dengan-negara-negara- anggota-organisasi-konferensi, diakses pada 25 September 2016).

Mankiw, N. Gregory. 2000. Teori Makro Ekonomi Edisi Keempat. Terjemahan: Imam Nurmawan. Jakarta: Erlangga.

Prasetya, Ning Yura Ika. 2014. Keterkaitan Sektor Transportasi Darat, Laut, dan Udara Terhadap Sektor-Sektor Ekonomi Lain Dalam Perekonomian Provinsi Jawa Timur. Skripsi tidak diterbitkan. Fakultas Ekonomi dan Bisnis Universitas Airlangga Surabaya.

Republic Indonesia. Undang-Undang Nomor 14 Tahun 1992 Tentang Lalu Lintas dan Angkutan Jalan. new York: John Willey and Son.

Salim, Abbas. 2002. Manajemen Transportasi. Jakarta: PT. Raja Grafindo Persada.

Sumarni, Murti. 2003. Pengantar Bisnis (Dasar-Dasar Ekonomi Perusahaan). Yogyakarta: Liberty Yogyakarta.

Shochrul R, Ajija, dkk. 2011. Cara Cerdas Menguasai EVIEWS. Jakarta: Salemba Empat.

Siregar, Akhirul Saleh. 2010. Analisis FaktorFaktor yang Mempengaruhi Pertumbuhan Ekonomi Kabupaten Labuhanbatu. Skripsi tidak diterbitkan. Fakultas Ekonomi Universitas Sumatera Utara.

Shihab, M. Quraish. 2002a. Tafsir AlMishbah. Volume 1. Jakarta: Lentera Hati.

Warpani, Suwardjoko P. 2002. Merencanakan Sistem Perangkutan. Bandung: Penerbit ITB. 